\title{
Patterns of COVID-19 on computed tomography imaging
}

\author{
SK Li *, FH Ng, KF Ma, WH Luk, YC Lee, KS Yung
}

\section{A B S T R A C T}

Purpose: As the designated tertiary referral centre for infectious diseases in Hong Kong, our hospital received the city's first group of patients diagnosed with coronavirus disease 2019 (COVID-19). Herein, we studied the earliest patients admitted to our centre in order to clarify the typical radiological findings, particularly computed tomography (CT) findings, associated with COVID-19.

Methods: From 22 January 2020 to 29 February 2020, 19 patients with confirmed COVID-19 underwent high-resolution or conventional CT scans of the thorax in our centre. The CT imaging findings of these patients with confirmed COVID-19 in Hong Kong were reviewed in this study.

Results: Ground-glass opacities (GGO) with peripheral subpleural distribution were found in all patients (100\%). No specific zonal predominance was observed. All lobes were involved in 16 (84.2\%) patients, focal subsegmental consolidations were observed in $14(73.7 \%)$ patients, and interlobular septal thickening was present in 12 (63.2\%) patients. No mediastinal lymph node enlargement, centrilobular nodule, or pleural effusion was features present in several patients include bronchial dilatation, bronchial wall thickening, and crazypaving patterns.

Conclusion: Peripheral subpleural GGO without zonal predominance in the absence of centrilobular nodule, pleural effusion, and lymph node enlargement were consistent findings in patients with confirmed COVID-19. The observed radiological patterns on CT scans can help identify COVID-19 and assess affected patients in the context of the ongoing outbreak.

\section{Hong Kong Med J 2020;26:289-93}

https://doi.org/10.12809/hkmj208521

SK Li *, MB, ChB, FRCR

FH Ng, FHKCR, FHKAM (Radiology)

KF Ma, FHKCR, FHKAM (Radiology)

WH Luk, FHKAM (Radiology), FRCR

YC Lee, FHKAM (Radiology), FRCR

KS Yung, MB, BS

Department of Radiology, Princess Margaret Hospital, Hong Kong detected in any of the patients. Other imaging *Corresponding author: leskileskileskileski@gmail.com

\section{New knowledge added by this study}

- Peripheral subpleural ground-glass opacities without zonal predominance in the absence of centrilobular nodules, pleural effusion, and lymph node enlargement were consistent findings in initial thoracic computed tomography scans of patients with coronavirus disease 2019 (COVID-19) in Hong Kong.

- Lung changes in patients with COVID-19 have no zonal predominance, which contrasts with the findings in patients with severe acute respiratory syndrome or Middle East respiratory syndrome, which predominantly affect basal zones.

Implications for clinical practice or policy

- Knowledge of common radiological patterns on computed tomography of the thorax can help discern the extent of pulmonary involvement and potentially facilitate identification of patients with pneumonia in Hong Kong during the COVID-19 outbreak.

- Air-space opacities are less frequent in patients with COVID-19 pneumonia, compared with patients with severe acute respiratory syndrome or Middle East respiratory syndrome, which implies that the course of COVID-19 pneumonia might be less aggressive.

\section{Introduction}

The Health Commission of Hubei province, China, first announced a cluster of patients with atypical pneumonia of unidentified pathogenic cause on 31 December 2019. ${ }^{1}$ The virus was isolated; its genome was then sequenced by a number of Chinese scientists who confirmed it to be a type of coronavirus. The virus was named severe acute respiratory syndrome coronavirus 2 (SARS-CoV-2), and the resulting disease was termed coronavirus disease 2019 (COVID-19) by the World Health Organization. ${ }^{2}$ The infectious disease centre at Princess Margaret Hospital, Hong Kong, is the designated local tertiary referral centre that provides treatment for patients diagnosed with COVID-19. Case reports available at the time of writing describe ground-glass lung 


\section{9 新型冠狀病毒病於電腦斷層掃描的表現}

\section{李思琪、吳豐謙、馬嘉輝、陸永恆、李應昌、容竟城}

目的：作為香港指定的傳染病第三層轉介中心, 本院接收了全港首批 2019 新型冠狀病毒病（COVID-19）患者。在此, 我們檢視最早入院 的患者以闡明與COVID-19相關的典型放射學表現, 尤其是電腦斷層 掃描 (CT掃描) 表現。

方法：2020年1月22日至2月29日期間, 我們對 19例確診COVID-19 的患者進行胸部高解像度或常規CT掃描。本研究回顧這些在香港確診 COVID-19的患者的CT掃描檢查結果。

結果：所有患者 $(100 \%)$ 的CT掃描顯示外圍胸膜下出現磨砂玻璃狀 影像, 大部份均散佈肺部不同區域。16例（84.2\%）的所有肺葉均受 累, 14例 $(73.7 \%)$ 的肺部出現局灶性亞節段實變, 12例 $(63.2 \%)$ 出現小葉間隔增厚。患者中未檢測到縱隔淋巴結腫大、小葉小結節或 胸腔積液。數例出現其他影像學特徵包括支氣管擴張、支氣管壁增厚 和碎石路徵。

結論：在確診COVID-19的患者, 其CT掃描均發現外圍胸膜下的磨 砂玻璃狀影像散佈肺部不同區域, 並且沒有出現小葉小結節、胸腔 積液和淋巴結腫大。在 CT掃描中觀察到的這種放射學模式有助識別 COVID-19, 並在持續爆發的情況下對受影響患者作出評估。
Radiographers who performed CT scans of patients with confirmed or suspected COVID-19 were required to wear full-body protective garments, in accordance with guidelines from infection control specialists. All radiographers wore disposable fluidresistant gowns, gloves, face shields, face masks with a rating of at least N95 (3M; Aberdeen [SD], United States), disposable shoe wraps, and protective eyewear. Patients were also required to wear masks with a rating of at least N95. All surfaces in contact with or within $1 \mathrm{~m}$ of the patients were cleaned with antiviral agents after completion of scanning. Cleaning procedures were performed twice; subsequently, the CT suite was not used for at least 30 minutes to allow for several air exchanges prior to the entry of the next patient.

The radiological images were reviewed and interpreted by consensus; the reviewers were two consultant radiologists who were registered specialist radiologists under Hong Kong Medical Council, Fellows of the Royal College of Radiologists, and Fellows of the Hong Kong College of Radiologists with 20 years of experience each in body CT.

\section{Results}

From 22 January 2020 to 29 February 2020, our hospital received 20 patients aged 25 to 80 years all with confirmed COVID-19 (Table). Chest radiographs were performed for all patients on admission; the most common finding was bilateral non-specific pulmonary infiltrates (Fig 1). Shortly after admission, 19 patients (11 men and eight women) underwent high-resolution CT or conventional plain CT thorax. One patient was asymptomatic and exhibited normal chest radiographs throughout the hospital stay; thus, no CT scans were performed for further evaluation. The median interval from confirmation of diagnosis to CT scanning was 3 days.

As indicated in the Table, ground-glass opacities (GGO) with peripheral subpleural distribution were observed in all patients (100\%) [Figs 2, 3a, b]. Furthermore, $57.9 \%$ of the patients exhibited diffuse involvement of both upper and basal zones, $15.8 \%$ demonstrated upper zone predominance, and 26.3\% demonstrated basal predominance. All lobes of the lungs were involved in 16 (84.2\%) patients (Fig 2), subsegmental consolidative changes were present in $14(73.7 \%)$ patients (Fig 3a, c), interlobular septal thickening was present in $12(63.2 \%)$ patients (Fig 3a), bronchial wall thickening or dilation was present in 10 (52.6\%) patients (Fig 3b), and crazy-paving patterns were present in six (31.6\%) patients (Fig 3). Mediastinal lymph node enlargement (ie, short axis $>1 \mathrm{~cm}$ ), centrilobular nodule, and pleural effusion were not detected in any of the patients.

In summary, peripheral subpleural GGO without zonal predominance in the absence of 
TABLE. Patient demographics and radiological findings $(n=19)$

\begin{tabular}{|c|c|}
\hline Characteristic & No. $(\%)$ of patients \\
\hline Median age, years (range) & $63(25-80)$ \\
\hline$<50$ & $6(31.6 \%)$ \\
\hline $50-64$ & $7(36.8 \%)$ \\
\hline$>64$ & $6(31.6 \%)$ \\
\hline \multicolumn{2}{|l|}{ Sex } \\
\hline Male & $11(57.9 \%)$ \\
\hline Female & $8(42.1 \%)$ \\
\hline $\begin{array}{l}\text { Median time from diagnosis to CT, } \\
\text { days (range) }\end{array}$ & $3(1-10)$ \\
\hline \multicolumn{2}{|l|}{ CT technique } \\
\hline High-resolution CT & $17(89.5 \%)$ \\
\hline Conventional CT & $2(10.5 \%)$ \\
\hline \multicolumn{2}{|l|}{ CT findings } \\
\hline GGO & $19(100 \%)$ \\
\hline Involvement of all lobes & $16(84.2 \%)$ \\
\hline Peripheral subpleural distribution & $19(100 \%)$ \\
\hline \multicolumn{2}{|l|}{ Zonal predominance } \\
\hline Upper & $3(15.8 \%)$ \\
\hline Basal & $5(26.3 \%)$ \\
\hline Diffuse & $11(57.9 \%)$ \\
\hline Interlobular septal thickening & $12(63.2 \%)$ \\
\hline Consolidation & $14(73.7 \%)$ \\
\hline Bronchial wall thickening or dilatation & $10(52.6 \%)$ \\
\hline Crazy-paving pattern & $6(31.6 \%)$ \\
\hline Centrilobular nodule & 0 \\
\hline Pleural effusion & 0 \\
\hline Lymph node enlargement & 0 \\
\hline
\end{tabular}

Abbreviations: $\mathrm{CT}$ = computed tomography; $\mathrm{GGO}=$ groundglass opacities

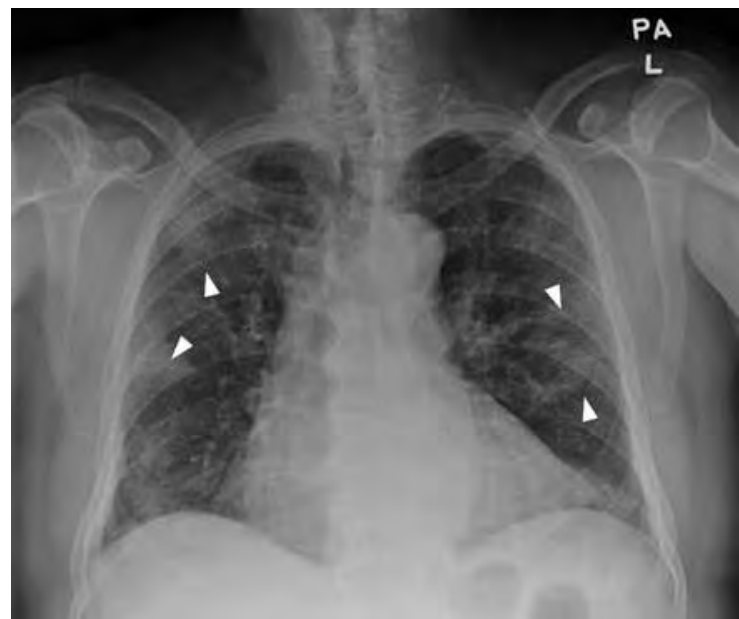

FIG I. A middle-aged man who travelled from Hubei province, presenting with fever and respiratory symptoms, was confirmed to have coronavirus disease 2019 (COVID-19). Chest radiograph on admission showed bilateral peripheral non-specific pulmonary infiltrates (arrowheads), a common finding among patients subsequently confirmed to have COVID-19

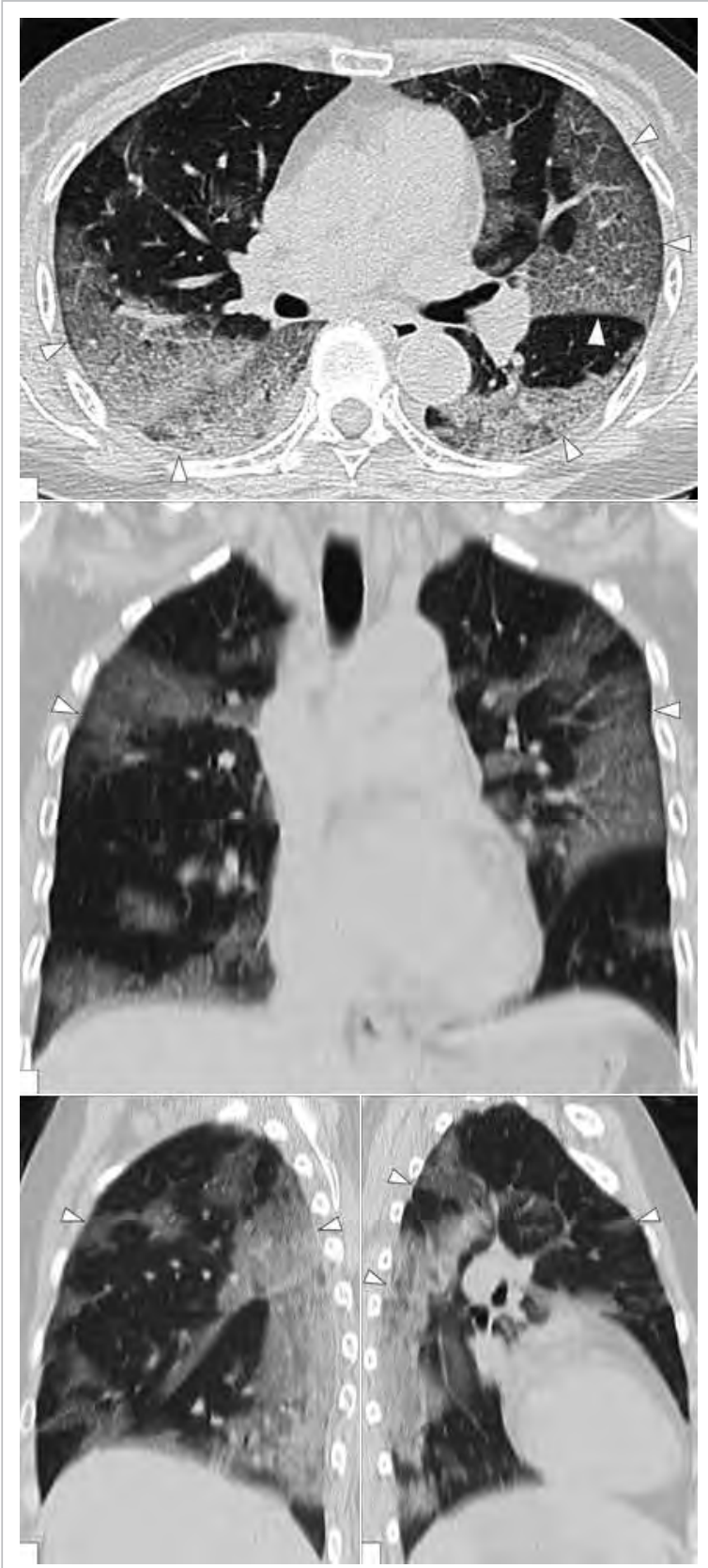

FIG 2. Computed tomography scan performed 4 days after the patient was confirmed to have coronavirus disease 2019 (COVID-19) showed bilateral ground-glass opacities in peripheral subpleural distribution (arrowheads) involving all lobes, in the absence of pleural effusion and lymph node enlargement, a pattern commonly encountered in our patients with COVID-19 pneumonia

centrilobular nodules, pleural effusion, and lymph node enlargement were consistent findings. Other common findings included septal thickening, consolidations, bronchial dilatation/wall thickening, and crazy-paving patterns.

\section{Discussion}

The most common respiratory pathogens are viruses. The imaging findings of viral pneumonia are 


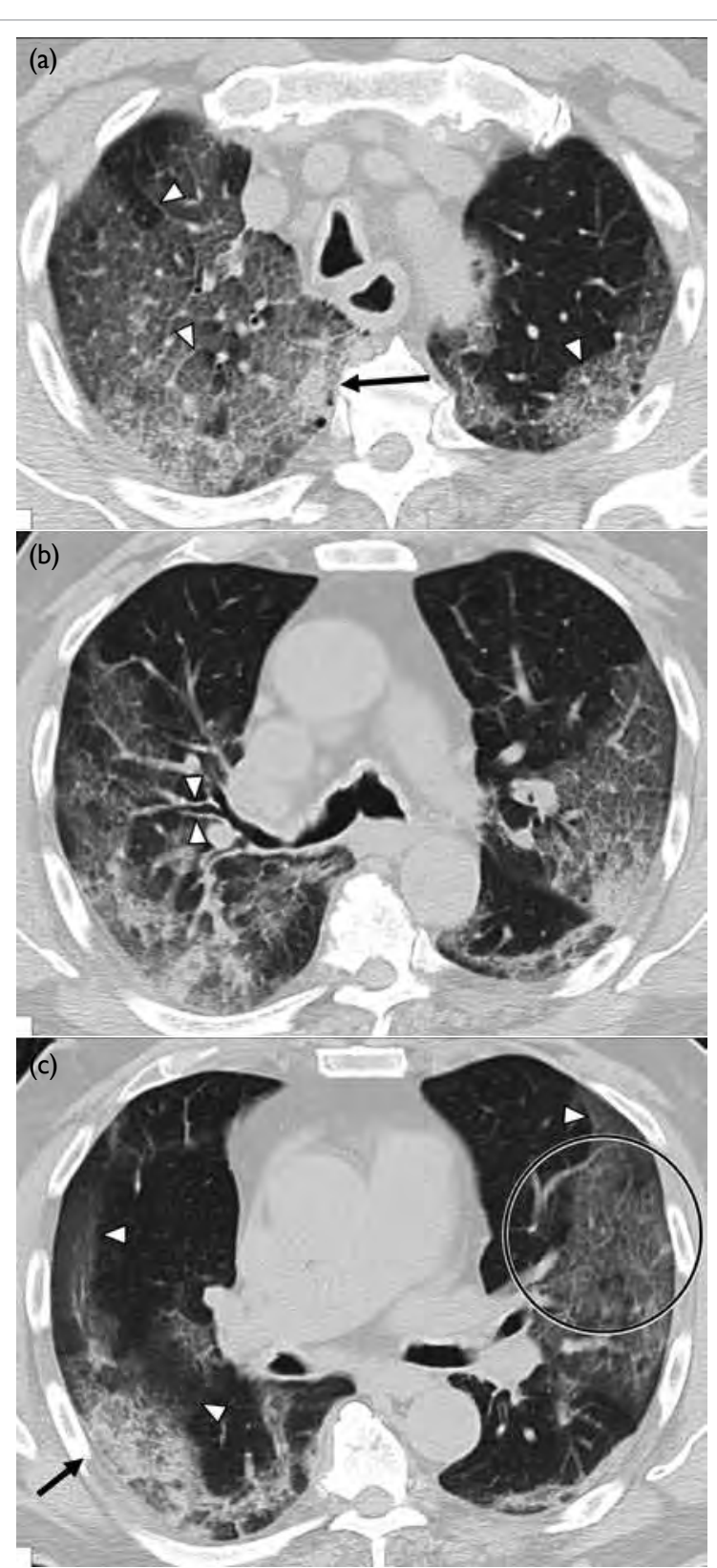

FIG 3. A patient with recent overseas travel history presented with fever and respiratory symptoms consistent with coronavirus disease 2019. (a) Axial computed tomography of thorax showed subsegmental consolidative changes over medial aspect of right upper lobe (arrow). Interlobular septal thickening was observed over bilateral upper lobes (arrowheads). Combined with ground-glass opacities, crazy-paving pattern was noted in right upper lobe. (b) Right lung bronchial wall thickening was present (arrowheads). (c) Peripherally located ground-glass opacities were noted in both lungs (arrowheads). Right lower lobe consolidative changes were present (arrow). Septal thickening and ground-glass opacities in left upper lobe constitute a crazy-paving pattern (circle). Lung changes involved all lobes diverse and often overlap with the findings of other non-viral pneumonias and inflammatory conditions. Imaging findings have been described in recent outbreaks associated with emerging pathogens, including severe acute respiratory syndrome (SARS) coronavirus and Middle East respiratory syndrome (MERS) coronavirus. ${ }^{6,7}$ Although a definite diagnosis cannot be reached based on imaging features alone, recognition of viral pneumonia patterns can aid in identification of potentially infected patients, especially during a specific viral outbreak.

Peripheral subpleural GGO without zonal predominance in the absence of pleural effusion and lymph node enlargement were consistent findings in initial thoracic CT scans of patients with COVID-19. These findings coincide with recent reports of single patients in which the major findings comprised multifocal patchy GGO, most evident around the periphery. ${ }^{3-5}$ Several other findings including bronchial wall thickening, bronchial dilatation, septal thickening, and crazy-paving patterns were also observed in a subset of patients.

Similar to our findings, diseases caused by other $\beta$-coronaviruses (eg, SARS, MERS, and other endemic human $\beta$-coronaviruses including OC43 and HKU1) are also characterised by multifocal peripheral GGOs. Moreover, patients infected with those viruses rarely exhibit cavitation, lymphadenopathy, or pleural effusions, ${ }^{6}$ similar to the findings in the present study. However, our study showed that lung changes in patients with COVID-19 have no zonal predominance, which contrasts with the findings in patients with SARS or MERS, which predominantly affect basal zones. ${ }^{6}$ Air-space opacities are less frequent in patients with COVID-19 pneumonia, compared with patients with SARS or MERS, which suggests that the course of COVID-19 pneumonia may be less aggressive. Nonetheless, conclusions should not be drawn prematurely as this study only involved the initial radiological assessment. More insights into the temporal changes regarding radiological findings during the progression of disease will become available as these patients undergo follow-up scans. Further studies that include the clinical course of COVID-19 in these patients will be performed in the future.

\section{Conclusion}

Coronavirus disease 2019 is a highly contagious disease that requires high vigilance and rapid detection. Knowledge of common radiological patterns on $\mathrm{CT}$ thorax can help discern the extent of pulmonary involvement and potentially facilitate identification of patients with pneumonia in Hong Kong during the COVID-19 outbreak. 


\section{Author contributions}

Concept or design: All authors.

Acquisition of data: All authors.

Analysis or interpretation of data: All authors.

Drafting of the manuscript: SK Li, FH Ng.

Critical revision of the manuscript for important intellectual content: SK Li, FH Ng.

All authors had full access to the data, contributed to the study, approved the final version for publication, and take responsibility for its accuracy and integrity.

\section{Conflicts of interest}

The authors have disclosed no conflicts of interest.

\section{Acknowledgement}

We would like to express our gratitude to the Infectious Disease Team and "dirty team" physicians of Princess Margaret Hospital, Hong Kong, for their professional patient care and invaluable contribution to the understanding of a novel disease.

\section{Funding/support}

This research received no specific grant from any funding agency in the public, commercial, or not-for-profit sectors.

\section{Ethics approval}

This study was carried out with approval from the Kowloon West Cluster Ethics Committee (Ref KW/EX-20-032(144-20)).
The requirement for patient consent was waived by the committee.

\section{References}

1. Centre for Health Protection, Hong Kong SAR Government. CHP closely monitors cluster of pneumonia cases on Mainland. 31 December 2019. Available from: https://www.info.gov.hk/gia/general/201912/31/ P2019123100667.htm. Accessed 1 Feb 2020.

2. World Health Organization. Clinical management of severe acute respiratory infection when COVID-19 is suspected. Interim guidance. 12 January 2020. Available from: https://www.who.int/publications-detail/clinicalmanagement-of-severe-acute-respiratory-infectionwhen-novel-coronavirus-(ncov)-infection-is-suspected. Accessed 1 Feb 2020.

3. Chan JF, Yuan S, Kok KH, et al. A familial cluster of pneumonia associated with the 2019 novel coronavirus indicating person-to-person transmission: a study of a family cluster. Lancet 2020;395:514-23.

4. Medlinkcn.com. 武漢19-nCoV 肺炎影像學表現初探 [in Chinese]. Available from: http://www.medlinkcn. com/?id=138. Accessed 1 Feb 2020.

5. Lei J, Li J, Li X, Qi X. CT imaging of the 2019 novel coronavirus (2019-nCoV) pneumonia. Radiology 2020;295:18.

6. Koo HJ, Lim S, Choe J, Choi SH, Sung H, Do KH. Radiographic and CT features of viral pneumonia. Radiographics 2018;38:719-39.

7. Franquet T. Imaging of pulmonary viral pneumonia. Radiology 2011;260:18-39. 